University of Nebraska - Lincoln

DigitalCommons@University of Nebraska - Lincoln

Publications, Agencies and Staff of the U.S.

Department of Commerce

U.S. Department of Commerce

$9-2004$

\title{
The alluring simplicity and complex reality of genetic rescue
}

David A. Tallmon

University of Alaska Southeast, david.tallmon@uas.alaska.edu

Gordon Luikart

University of Montana, gordon.luikart@umontana.edu

Robin Waples

NOAA, robin.waples@noaa.gov

Follow this and additional works at: https://digitalcommons.unl.edu/usdeptcommercepub

Tallmon, David A.; Luikart, Gordon; and Waples, Robin, "The alluring simplicity and complex reality of genetic rescue" (2004). Publications, Agencies and Staff of the U.S. Department of Commerce. 480. https://digitalcommons.unl.edu/usdeptcommercepub/480

This Article is brought to you for free and open access by the U.S. Department of Commerce at DigitalCommons@University of Nebraska - Lincoln. It has been accepted for inclusion in Publications, Agencies and Staff of the U.S. Department of Commerce by an authorized administrator of DigitalCommons@University of Nebraska - Lincoln. 


\title{
The alluring simplicity and complex reality of genetic rescue
}

\author{
David A. Tallmon ${ }^{1}$, Gordon Luikart ${ }^{1}$ and Robin S. Waples ${ }^{2}$
}

'Laboratoire d'Ecologie Alpine, Génomique des Populations et Biodiversité, CNRS UMR 5553, Université Joseph Fourier, BP 53, 38041 Grenoble, Cedex 09, France

${ }^{b}$ National Marine Fisheries Service, Northwest Fisheries Science Center, 2725 Montlake Boulevard East, Seattle, WA 98112, USA

\begin{abstract}
A series of important new theoretical, experimental and observational studies demonstrate that just a few immigrants can have positive immediate impacts on the evolutionary trajectory of local populations. In many cases, a low level of immigration into small populations has produced fitness benefits that are greater than those predicted by theoretical models, resulting in what has been termed 'genetic rescue'. However, the opposite result (reduced fitness) can also be associated with immigration of genetically divergent individuals. Central to our understanding of genetic rescue are complex interactions among fundamental concepts in evolutionary and population biology, including both genetic and non-genetic (environmental, behavioral and demographic) factors. Developing testable models to predict when genetic rescue is likely to occur is a daunting challenge that will require carefully controlled, multigeneration experiments as well as creative use of information from natural 'experiments'.
\end{abstract}

The complex interplay of gene flow, mutation, drift and selection in natural populations makes it difficult to predict which evolutionary force will be most important at any particular time or place [1]. For many years, the demographic contribution of immigrants received the primary emphasis in the literature [2-4], based on the premise that the genetic effects of small population size are less important than are other factors in determining population persistence [5]. More recently, it has been shown unequivocally that inbreeding resulting from genetic drift in small populations can depress POPULATION FITNESS (see Glossary) and increase extinction risk [6-9]. In an exciting new development, a variety of natural and experimental studies demonstrate that immigrants can effect a GENETIC RESCUE [10] of small, inbred, at-risk populations by alleviating INBREEDING DEPRESSION and boosting fitness.

Genetic rescue is generally considered to occur when population fitness, inferred from some demographic vital rate or phenotypic trait, increases by more than can be attributed to the demographic contribution of immigrants $[11,12]$. (In human medicine, genetic rescue is used in reference to gene therapy, but this usage lies outside the scope of this article.) Genetic rescue might play a subtle, yet crucial role in the evolution of small natural populations and can, under some circumstances, be an effective conservation tool. Evidence that genes from a pulse of immigrants can increase population growth rate also has important implications for the study of METAPOPULATION dynamics [13].

However, immigration of genetically divergent individuals can also lead to the opposite effect: a reduction in population fitness owing to OUTBREEDING DEPRESSION. Whether immigrants increase or reduce population fitness depends upon interactions among several genetic and nongenetic factors, such as the degree of EPISTASIS, demography, behavior and environmental context. This complexity makes it difficult to predict whether any given immigration event will effect genetic rescue. Results of recent studies should help to re-focus research toward a fuller understanding of the evolutionary consequences of migration among small populations, as researchers focus more upon the complex interactions among forces that underlie the evolution of spatially structured populations.

\section{Fitness effects of immigrant genes}

The fundamental premise of genetic rescue is that, if a local population suffers inbreeding depression, immigrants can infuse new genetic variation that increases fitness. Under this scenario, immigrants must produce descendants that are, on average, more fit than those of

\footnotetext{
Glossary

Epistasis: interactions among genes at different loci that influence a phenotypic trait.

Genetic rescue: an increase in population fitness owing to immigration of new alleles.

Heterosis: elevated fitness of offspring from matings between genetically divergent individuals (i.e. hybrid vigor).

Inbreeding depression: reduced fitness of offspring from matings between related individuals, owing to reduced heterozygosity and/or increased expression of deleterious, recessive alleles.

Intrinsic coadaptation: elevated fitness caused by positive epistasis.

Local adaptation: increase in fitness of a local population associated with an increase in the frequency of alleles or allelic combinations favored by local selection pressures.

Metapopulation: a population of populations linked by migration; in the classic definition, local populations are subject to frequent extinction and recolonization events.

Outbreeding depression: reduced fitness of offspring from matings between genetically divergent individuals, owing to dilution of local adaptation and/or disruption of epistasis.

Population fitness: mean fitness measured as population growth rate or inferred from changes in reproduction or survival rates.
} 
residents to then raise the overall mean fitness of the local population. Ideally, genetic rescue is measured by an increase in population growth rate over multiple generations.

The increase in fitness is thought to be due primarily to HETEROSIS in the offspring that result from matings between immigrants and local individuals. Heterosis occurs via two mechanisms. First, immigrant alleles can mask deleterious, recessive alleles that have achieved a high local frequency via genetic drift, which can occur when the product of population size $(N)$ and the selection coefficient $(\mathrm{s})$ is less than one $\left(N_{\mathrm{s}}<1\right)$. Second, matings between immigrants and local individuals produce highly heterozygous offspring, which are often favored by natural selection. The recent literature suggests masking of deleterious alleles is the more prevalent mechanism of heterosis [14].

To understand how immigration can either increase or reduce population fitness, it is necessary to consider multiple gene loci over multiple generations (Figure 1). The F1 generation will have high heterozygosity (and, hence, heterosis) as a result of allele frequency differences between parental types. Positive epistasis will also be maintained because one set of chromosomes from each parental lineage remains intact. However, immigration will also decrease LOCAL ADAPTATION by diluting local alleles that make positive additive contributions to fitness. Therefore, the net fitness effects of immigration in the F1 generation can be either positive or negative, depending on whether the positive effects of heterosis more than compensate for the dilution of local adaptation.

In subsequent generations (F2 and beyond), recombination will disrupt positive epistatic interactions among parental alleles at different loci (Figure 1), thus reducing INTRINSIC COADAPTATION. If the immigration rate is high and from a genetically divergent source, population fitness can be reduced in the F2 generation and beyond as immigrants dilute locally adaptive alleles and disrupt coadapted gene complexes. Furthermore, heterozygosity and associated heterosis peaks in the F1 generation and declines thereafter. As a consequence, descendants of immigrants often exhibit initial heterosis followed by subsequent outbreeding depression in following generations (Box 1), so whether a population is rescued genetically by immigrants largely depends on the relative importance of these opposing phenomena.

\section{Observational studies of genetic rescue}

Several recent studies report increased fitness in response to low levels of immigration (gene flow) into populations that have suffered recent declines (Table 1). For example, immigrants apparently increased the hatching rate of imperiled prairie chickens Tympanuchus cupido [15] and reduced the proportion of stillborn births in a relict population of adders Vipera berus, while increasing molecular genetic variation, recruitment and population growth rate [16]. A single immigrant is thought to have spurred the growth of a stagnant, recently re-founded Scandinavian wolf Canis lupus population [17,18].

These studies, which encompass a wide range of vertebrate taxa, suggest that immigration can increase

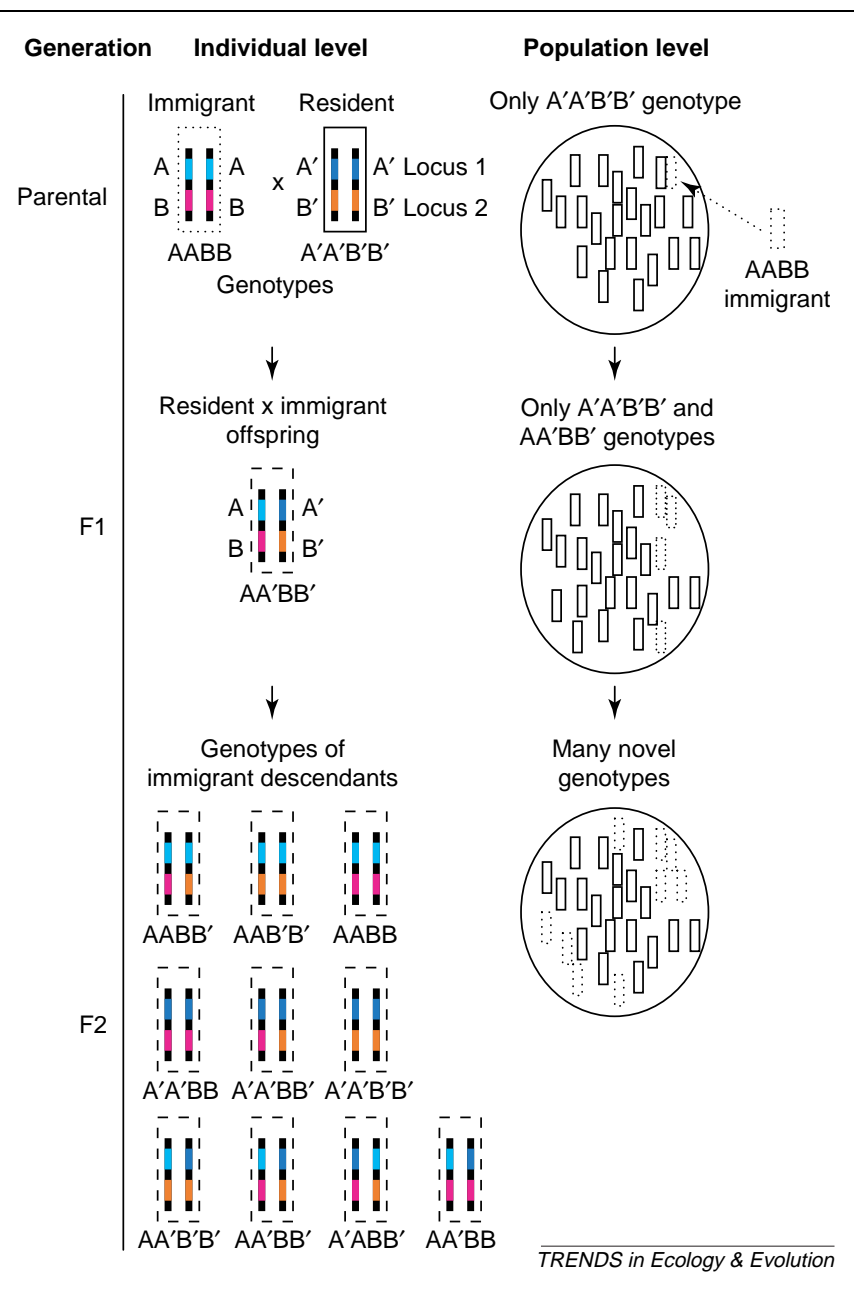

Figure 1. Genetic rescue. Genetic rescue depends upon whether selection favors the new genotypes created by immigration. The mating of a genetically divergent immigrant (homozygous for one set of alleles $A$ and $B$ at loci 1 and 2, respectively) with an individual from a local population (homozygous for different alleles $A^{\prime}$ and $\left.B^{\prime}\right)$ produces $F 1$ offspring that are heterozygous and adds genetic variation to the population. By the F2 generation, this mating generates ten possible genotypes at two loci. In real populations, there are many more loci and novel genotypes generated by immigration events.

the fitness of small, inbred populations by restoring adaptive genetic variation. However, because each of these studies was limited to a single, unreplicated population without experimental controls, it is impossible to attribute unequivocally the fitness increases to genetic rescue rather than to other potentially confounding factors, such as benign changes in the local environment or non-genetic influences of immigrants. For example, it is possible that the Scandinavian wolves were so closely related they simply avoided breeding for behavioral reasons until the unrelated immigrant arrived [17].

\section{Experimental studies of genetic rescue}

Other recent studies have isolated the genetic influences of immigrants by controlling for their demographic impacts, and they support the premise that immigration can increase population fitness [19-23]. The most striking example of genetic rescue is from a water flea Daphnia magna metapopulation inhabiting Baltic seashore rockpools [19]. In replicate populations, the researchers mated residents with residents, residents with immigrants and 


\section{Box 1. Heterosis and outbreeding depression}

Initial heterosis, followed by outbreeding depression, has been observed recently in taxa as diverse as angiosperms [62,63], copepods [64], insects [65], birds [66] and mammals [67]. In the marine copepod Tigriopus californicus, Burton, Edmands and colleagues found heterosis in F1 hybrids followed by F2 outbreeding depression levels that correlated with the genetic divergence between source and recipient populations $[64,68,69]$. In Fenster and Galloway's studies of the partridge pea Chamaecrista fasciculate, F1 crosses of individuals from populations at all distances studied $(0.1-2000 \mathrm{~km})$ showed heterosis, thus demonstrating inbreeding depression within populations $[62,63,70]$. Subsequently, outbreeding depression was found in crosses from populations separated by $\geq 1000 \mathrm{~km}$, but not until the F3 generation. Because unlinked genes begin recombining in the F2 generation, the appearance of consistent outbreeding depression only in the F3 generation demonstrates that disruption of epistasis as a result of linked genes can continue to reduce fitness beyond the F2 generation. Evidence also suggests that cytonuclear co-adaptations (i.e. the coadaptation of nuclear and cytoplasmic organelle genes) can contribute to outbreeding depression $[70,71]$.

In a remarkable example of intrinsic coadaptation, Gharrett et al. found outbreeding depression in crosses of two pink salmon Oncorhynchus gorbuscha populations that spawn in the same location (and, hence, experience on average the same environment) but are isolated temporally because of strict even- or odd-year life cycles [72]. Inter-year crosses showed outbreeding depression in the F2 (but not F1) generation, which provides evidence for disruption of positive epistasis following recombination. These theoretical results help to explain that even the same selection pressures (on average) over many generations do not guarantee a similar genetic architecture, which, in turn, suggests that extensive mixing of populations experiencing similar selective regimes might increase fitness in real populations.

immigrants with immigrants. Repeated generations of asexual reproduction locked in place F1 genotypes. Because asexual reproduction prevented segregation of alleles, selection could act over many generations on intact resident, F1 hybrid, and pure immigrant genomes and amplify fitness differences among lineages over time. Ultimately, the hybrid F1 clonal lineages had an average fitness that was over 35 times that of resident lineages.

This study demonstrates that inbreeding depression is a biologically important phenomenon in this water flea metapopulation and that immigration can increase fitness greatly. Because entire life cycles were observed, fitness impacts were integrated over the full life history and amplified over time. By contrast, most studies infer fitness effects of experimental treatments on only one or two traits measured in a single generation. Selection intensity on individual life history traits can vary greatly over time and space, and the cumulative effects of selection on multiple traits will interact to produce overall fitness effects. This implies that short-term studies of a few traits can result in misleading conclusions. For example, Bryant et al. found a strong genetic rescue effect on larval emergence in experimental house fly Musca domestica populations, but only after an initial five-generation period in which low levels of immigration provided no detectable benefits to recipient populations [20].

Two recent plant studies provide further evidence of the fitness benefits immigrants can provide to inbred populations. In experimentally inbred populations of the mustard Brassica campestris, one immigrant per generation significantly increased the fitness of four out of six fitness traits in treatment populations compared with (no immigrant) controls [21]. No fitness difference was found between the one-immigrant and 2.5-immigrant treatments, which suggests that only very low levels of immigration are necessary for a fitness boost. However, greater phenotypic divergence among populations was found in the one-immigrant treatment compared with 2.5immigrant treatment. This is interesting because it shows that lower immigration can facilitate local adaptation in spatially structured populations that are subject to variable or divergent selection pressures.

In small white campion Silene alba populations, gene flow increased germination success and the success of immigrant pollen correlated positively with the amount of inbreeding in recipient populations [22,24]. This work demonstrates inbreeding depression in these populations and suggests that, all else being equal, populations that are more inbred are more likely to benefit from a genetic rescue effect. Together with the Brassica study and others [23,25-28], this implies that very low levels of immigration could cause genetic rescue in inbred populations without greatly constraining local adaptation. Fortunately, it is increasingly possible to identify recently inbred populations using new molecular-based statistical approaches [29], and so candidate populations for genetic rescue should be easier to find.

\section{Rescue via other genetic pathways}

Immigrants can also increase fitness via mechanisms other than heterosis [12,30]. One such mechanism is frequency-dependent selection for rare alleles. In small populations of self-incompatible plants with few alleles at the S-locus (which inhibits pollination by donors with the same S-allele type as the maternal plant), immigrant pollen with novel S-alleles can substantially increase reproductive success [31-33]. There is also evidence in Hymenoptera that frequency-dependent selection for novel sex-determining alleles introduced into bottlenecked populations by immigrants would raise colony fitness by increasing the frequency of diploid heterozygotes (females, which contribute to colony success), at the expense of diploid homozygotes (males, which drain resources) [34].

Gemmell and colleagues hypothesize that female immigrants might also benefit small populations by introducing new mitochondrial DNA (mtDNA) alleles, which are maternally inherited in most species [35]. They suggest that mtDNA alleles with negative fitness effects (e.g. on male fertility) would become fixed in small populations, because selection acts less efficiently (and differently) on mtDNA alleles, owing to their maternal inheritance, than it does on nuclear alleles [36]. In this scenario, immigrant females that pass on superior mtDNA alleles would boost population fitness with their extranuclear genetic contributions.

\section{Inferences for metapopulation conservation}

The upshot of these recent studies is that genetic rescue could be crucially important to entire metapopulations by reducing local inbreeding depression or adding adaptive 
Table 1. Recent empirical studies showing genetic rescue effects ${ }^{a}$

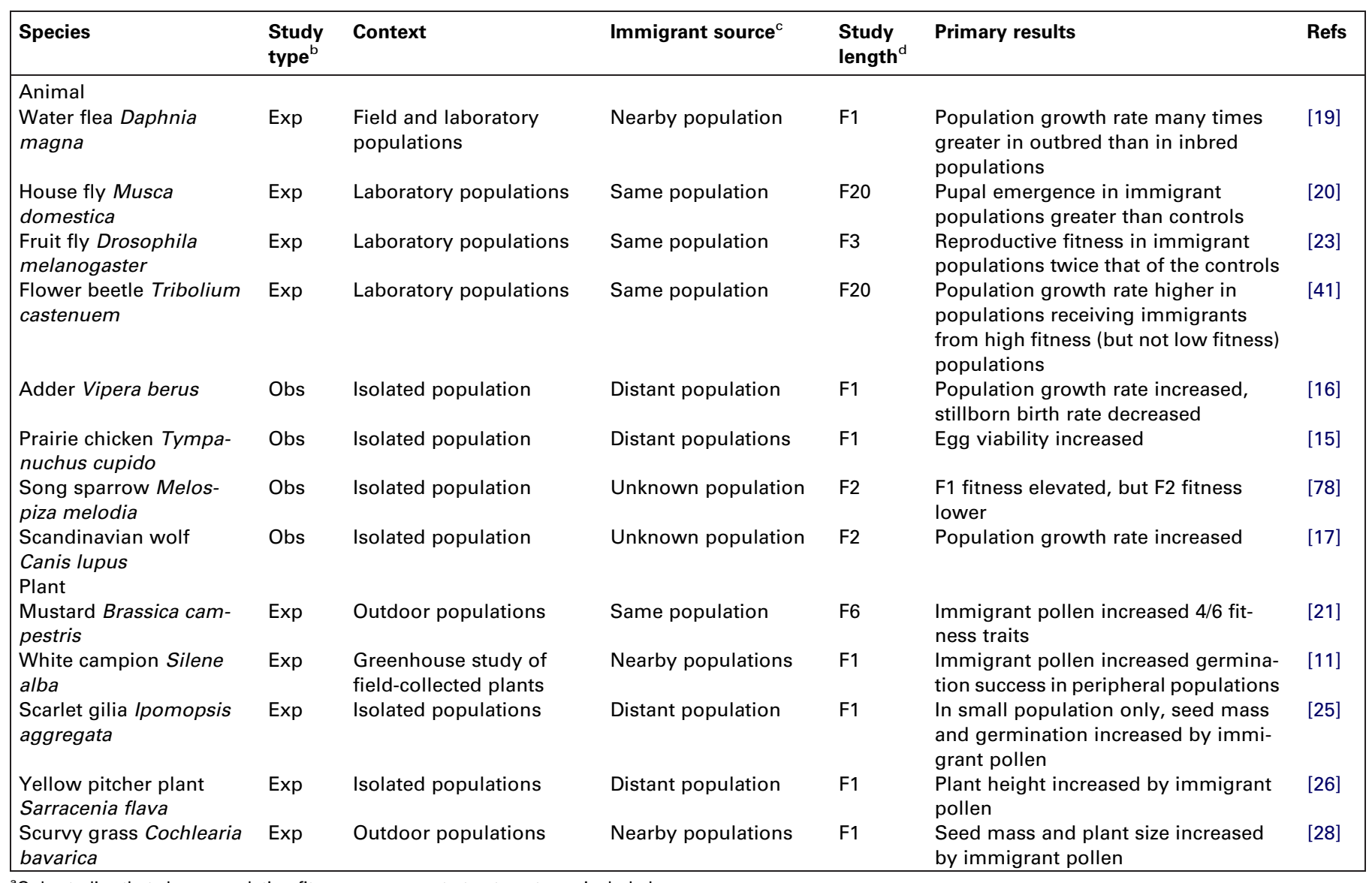

${ }^{a}$ Only studies that show population fitness responses to treatments are included.

bobs, observational; Exp, experimental.

'Source population for immigrant individuals. In many experiments, immigrants are recent descendants from same source as recipient populations

dinferred study length in generations from first immigration event, sometimes not explicitly stated in studies.

alleles that increase the probability of local population persistence. In turn, this bolstering of local populations maintains a broad geographical distribution of populations that buffers overall metapopulation extinction and provides future immigrants for other populations [10]. A genetic rescue effect can improve the likelihood of success of colonization events that might otherwise fail because immigrants can reinforce colonizing populations that often evolve from a few founders and quickly become inbred $[17,22]$. From a conservation perspective, this also means that genetic rescue might have an important impact in the spread of unwanted invasive species along the leading edge of invasion by supplying recently established, small propagules with adequate genetic variation to respond to selection and adapt to the new environment [37]. Therefore, a useful strategy for reducing the spread of invasive populations could be to minimize the chances for genetic rescue to occur.

Although the term 'genetic rescue' is new, the underlying concepts are not. Similar to many other useful concepts in evolution, the thread of genetic rescue can be traced back to Charles Darwin and Sewall Wright (Box 2). Recent theory has refined our understanding of genetic rescue and shown that heterosis is maximized when local population size is small, gene flow is low and selection intensity is low or intermediate $[38,39]$. These results are germane, because reductions in local population size (and, hence, greater drift and less efficient natural selection) and restrictions in gene flow are two of the primary consequences of the ongoing worldwide habitat fragmentation crisis [40]. This suggests that anthropogenic influences will increase the number of cases where genetic rescue will be an important evolutionary phenomenon and effective conservation tool.

\section{Complicating genetic factors}

In spite of these exciting results, several important caveats apply to the laboratory and field studies reporting genetic rescue that should temper the use of genetic rescue as a management tool. First, most laboratory studies have used highly inbred lines or populations. The level of inbreeding typically was equivalent to full-sib mating for two generations or more, so it is not surprising that mating with an immigrant would provide fitness benefits. It is difficult to translate these experimental results directly to natural populations in which inbreeding levels are usually unknown and unlikely to be as high.

Second, the experimental populations and immigrants are usually derived from a single source population. Given that immigrants share a common genetic architecture with the recipient population, the chances of outbreeding depression are reduced. Finally, most studies have 


\section{Box 2. The conceptual foundations of genetic rescue}

The concept of genetic rescue was presaged by Charles Darwin, who, in his extensive surveys of empirical data to better understand evolutionary processes, noted that (i) isolated populations often suffer from inbreeding and inbreeding depression, and that (ii) immigration ('new blood') can help recover a population's fitness [73]. Although Darwin's observations are over 100 years old and report insights from husbandry that probably extend back millennia to the early days of domestications, theory to understand these observations is still being developed.

The seminal theoretical work relevant to genetic rescue was proposed by Sewall Wright, who was interested in the effects of immigration among populations linked by gene flow. He showed that one migrant per generation among populations equally linked by immigration was adequate to keep the same neutral alleles segregating in all populations, and that the relative strength of gene flow and selection determined the fate of non-neutral alleles [74,75]. Wright's

followed results only through the F1 generation, where heterosis is maximized and outbreeding depression is often not yet expressed.

Still, although there is no doubt that immigration from a maladapted source can reduce fitness and constrain local adaptation [41-43], the idea that limited immigration can play a more positive role in evolution has received renewed attention [41,44-46]. A key to resolving the general importance of genetic rescue is understanding the relative importance of interactions among genes versus the additive effects of individual genes in determining the fitness of populations - a debate that dates back to Fisher and Wright and remains an area of active research. Some recent experimental results suggest that, if favored alleles are added to a population, they will spread because selection can efficiently choose advantageous alleles regardless of the genetic background [47]. This implies that gene interactions might not be as important as single locus, additive contributions to fitness and that, under some circumstances, at least, selection can take care of things if given enough time and a few copies of adaptive alleles to act upon. Thus, immigrants can provide useful alleles that, over long timescales, contribute to increased population fitness even if the immediate descendants of immigrants do not.

\section{Complicating non-genetic factors}

Given that individuals are not boxes of genes, demographic, behavioral and environmental factors can profoundly influence the fitness contributions of immigrants (Box 3). Demographic theory has predicted, and empirical studies have demonstrated, that individuals of particular ages or life stages can have disproportionate effects on the trajectory of a population. Using standard demographic data and analyses [48,49], one can predict the relative impacts of immigrants by estimating their future reproductive potential. For example, immigrants have little chance of providing genetic rescue if they are immature and have a low chance of survival to reproductive age, or are too old and have little chance of future reproduction. Joint consideration of demography and genetics in a single theoretical framework can sharpen predictions of optimal conditions for genetic rescue [50,51]. However, subtleties of how demography is incorporated into population genetic contributions remain the foundation for much of the ongoing research related to population subdivision, migration and the distribution of genetic variation in neutral and selected loci and traits.

Recent models by Whitlock and colleagues have expanded Wright's work to include heterosis in immigrant offspring $[38,39]$. These efforts demonstrate that, as small isolated populations diverge, they become fixed for different deleterious alleles at different loci. As a result, immigrants bring in alleles that mask local deleterious alleles, immigrant offspring show higher fitness than local offspring, and the effective immigration rate (i.e. gene flow) is elevated over that expected from neutral theory as immigrant alleles increase rapidly in frequency owing to selection. These results help to explain some of the recent remarkable results from the laboratory and field, even though they are based upon simple single-locus population genetic models and do not include heterozygote advantage or other genetic mechanisms that might increase fitness.

models can alter conclusions, so careful examination of assumptions is necessary $[52,53]$.

Even a rigorous investigation of genetic and demographic factors might be insufficient to predict reliably whether genetic rescue will occur, because important behavioral subtleties such as mate choice, dominance hierarchies and infanticide, can also influence the evolutionary impact of immigrants. For example, female mice Mus domesticus prefer genetically dissimilar males, which would favor immigrant males and facilitate genetic rescue. However, they also assess male quality, in addition to genetic dissimilarity, in choosing among potential mates [54], which complicates predictions of how well immigrant males might reproduce.

Furthermore, in some species, a successful male immigrant might kill existing juveniles, as occurs, for example, with immigrant adult male brown bears Ursus arctos following removal of local adult males by hunters [55]. In general, immigrants could have widely varying reproductive success depending upon interactions with local individuals. Thus, they could provide either no, or a great deal, of gene flow, which makes tenuous studies uninformed by behavioral or mating system data [56].

Immigrants might also serve as vectors for diseasecausing parasites and pathogens, thus leading to the opposite of a rescue effect [57,58]. Little empirical evidence is available to indicate under what conditions the genetic rescue benefits of low levels of immigration outweigh the increased risk of disease transfer.

From the above considerations, it is clear that, even if one considers only biological consequences for the species of interest, evaluating and predicting the consequences of a genetic rescue attempt is exceedingly complex. In a conservation context, biological theory can provide insights, but broader considerations are also likely to be relevant. For example, genetic rescue efforts for some atrisk species have economic, social, legal and political ramifications. Integrating these types of consideration into an overall cost-benefit analysis will be challenging but necessary [59].

\section{Future studies}

A nagging limitation is how little we know about the joint impacts of inbreeding and outbreeding depression in 


\section{Box 3. The biological context of genetic rescue}

In applying the concept of genetic rescue to wild populations, much information is needed. Ideally, detailed behavioral, demographic, environmental and genetic information would be available to provide a comprehensive framework for understanding when rescue might be achieved (Figure I). First, it is important to know how much a population suffers from inbreeding depression and how susceptible it is to outbreeding depression. This will determine the optimal level of immigration to effect a fitness increase. However, the balance between these two considerations in wild populations is difficult to ascertain because it depends upon many usually unknown factors.

Conservation efforts on behalf of the endangered Florida panther Felis concolor, which has shown strong putative inbreeding depression, have attempted to integrate some of these factors. Hedrick used simple population genetics models to show that a brief period of high gene flow followed by subsequent generations of low gene flow could effect genetic rescue by reducing the frequency of deleterious alleles without substantially reducing the frequency of locally adaptive alleles [76]. Knowledge of panther behavior suggested that only females should be used as immigrants because males were likely to precipitate mortal combat with resident males, risking not only local population decline, but also the failure of immigrants to reproduce. It was also known that females readily establish territories and begin breeding after their first year.

These behavioral, genetic, and demographic considerations were incorporated into Florida panther recovery management actions and preliminary evidence suggests that the initial target level of introgression has been achieved and that at least one important fitness trait, the number of descended testicles per male, has increased [77]. Several generations of monitoring will be necessary to see if this attempted genetic rescue is successful in boosting population growth.

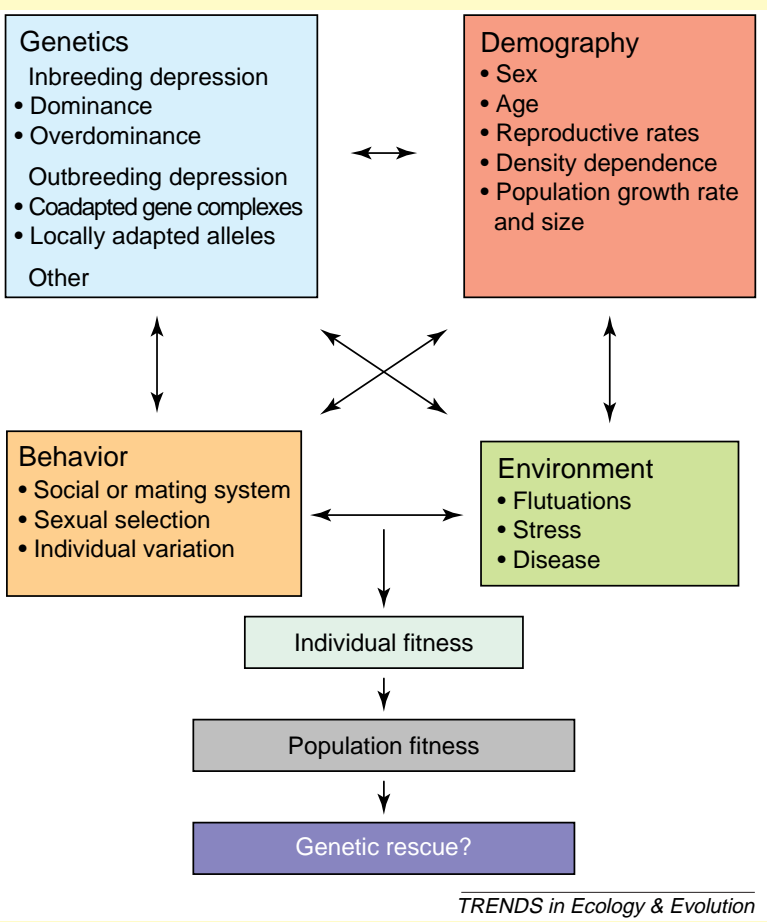

Figure I. Some of the important biological factors that interact to determine whether genetic rescue will occur.

natural populations, except that they probably occur frequently and simultaneously [60]. A key evolutionary question is whether the heterotic effects of a few successful immigrants will outweigh reductions in fitness owing to outbreeding depression. Susceptibility to these two factors varies considerably among taxa and specific circumstances, including population history and recent inbreeding levels, degree of local adaptation and genetic divergence between immigrants and recipient populations. Given the paucity of data addressing this issue for wild or experimental populations, it is difficult to predict with any certainty whether the net genetic effects will be positive or negative for any unstudied system. This is a sobering truth for applied conservation efforts. However, empirical data do demonstrate that low levels of immigration can provide considerable fitness benefits to recently isolated, inbred populations, and recent molecular-based statistical advances will help to identify these populations efficiently [29,61].

A daunting challenge is to develop a general theory of rescue effects that incorporates genetics, in addition to demography, behavior and disease ecology; all factors that can be shown to be of preeminent importance in specific cases. The crux of the challenge is formulating theories that are simple enough to be tested empirically and that are useful beyond only narrow conditions. There is a vital role for multi-generation experiments in developing this theory, as well as for creative uses of meta-analyses to distill collective insights from numerous imperfectly controlled laboratory and natural 'experiments'.

\section{Acknowledgements}

We thank Jeff Hard, Jack Hogg, Laurent Keller, and especially Fred Allendorf for helpful comments. This article was written while D.A.T. was supported by NSF (INT 0202707) and G.L. was supported by European Commission (QLK5-CT-2001-02461). R.S.W. contributed while a visiting scientist at Laboratoire d'Ecologie Alpine.

\section{References}

1 Grant, P.R. and Grant, B.R. (2002) Unpredictable evolution in a 30year study of Darwin's finches. Science 296, 707-711

2 Brown, J. and Kodric-Brown, A. (1977) Turnover rates in insular biogeography: effect of immigration on extinction. Ecology 58, 445-449

3 Stephens, P.A. and Sutherland, W.J. (1999) Consequences of the Allee effect for behaviour, ecology, and consequences. Trends Ecol. Evol. 14, 401-405

4 Courchamp, F. et al. (1999) Inverse density dependence and the Allee effect. Trends Ecol. Evol. 14, 405-410

5 Caughley, G. (1994) Directions in conservation biology. J. Anim. Ecol. $63,215-244$

6 Keller, L.F. et al. (1994) Selection against inbred song sparrows during a natural population bottleneck. Nature $372,356-357$

7 Keller, L.F. (1998) Inbreeding and its fitness effects in an insular population of song sparrows (Melospiza melodia). Evolution 52, 240250

8 Newman, D. and Pilson, D. (1997) Increased probability of extinction due to decreased genetic effective population size: experimental populations of Clarkia pulchella. Evolution 51, 354-362

9 Saccheri, I.J. et al. (1998) Inbreeding and extinction in a butterfly metapopulation. Nature 392, 491-494

10 Thrall, P.H. et al. (1998) Metapopulation collapse: the consequences of limited gene-flow in spatially structured populations. In Modeling Spatiotemporal Dynamics in Ecology (Bascompte, J. and Sole, R.V. eds), pp. 83-104, Springer Verlag

11 Richards, C.M. (2000) Genetic and demographic influences on population persistence: gene flow and genetic rescue in Silene alba. In Genetics, Demography and Viability of Fragmented Populations (Young, A.G. and Clarke, G.M. eds), pp. 271-291, Cambridge University Press

12 Ingvarsson, P.K. (2001) Restoration of genetic variation lost - the genetic rescue hypothesis. Trends Ecol. Evol. 16, 62-63

13 Gaggiotti, O.E. and Hanski, I. (2004) Mechanisms of population 
extinction. In Ecology, Genetics, and Evolution of Metapopulations (Hanski, I. and Gaggiotti, O.E. eds), pp. 337-366, Elsevier Academic Press

14 Remington, D.L. and O'Malley, D.M. (2000) Whole-genome characterization of embryonic stage inbreeding depression in a selfed loblolly pine family. Genetics $155,337-348$

15 Westermeier, R.L. et al. (1998) Tracking the long-term decline and recovery of an isolated population. Science 282, 1695-1698

16 Madsen, T. et al. (1999) Restoration of an inbred adder population. Nature 402, 34-35

17 Vila, C. et al. (2002) Rescue of a severely bottlenecked wolf (Canis lupus) population by a single immigrant. Proc. r. Soc. Lond. Ser. B. 270, 91-97

18 Ingvarsson, P.K. (2003) Lone wolf to the rescue. Nature 420, 472

19 Ebert, D. et al. (2002) A selective advantage to immigrant genes in a Daphnia metapopulation. Science 295, 485-488

20 Bryant, E.H. et al. (1999) Experimental tests of captive breeding for endangered species. Conserv. Biol. 13, 1487-1496

21 Newman, D. and Tallmon, D.A. (2001) Experimental evidence for the beneficial fitness effects of gene flow in recently isolated populations. Conserv. Biol. 15, 1054-1063

22 Richards, C.M. (2000) Inbreeding depression and genetic rescue in a plant metapopulation. Am. Nat. 155, 383-394

23 Spielman, D. and Frankham, R. (1992) Modeling problems in conservation genetics using Drosophila populations: improvement of reproductive fitness due to immigration of one individual into small partially inbred populations. Zoo Biol. 11, 343-351

24 Richards, C.M. et al. (1999) The influence of population size and isolation on gene flow by pollen in Silene alba. Evolution 53, 63-73

25 Heschel, M.S. and Paige, K.N. (1995) Inbreeding depression, environmental stress, and population size variation in scarlet gilia, Ipomopsis aggregata. Conserv. Biol. 9, 126-133

26 Sheridan, P.M. and Karowe, D.N. (2000) Inbreeding, outbreeding, and heterosis in the yellow pitcher plant, Sarracenia flava, in Virginia. Am. J. Bot. 87, 1628-1633

27 Saccheri, I.J. and Brakefield, P.M. (2002) Rapid spread of immigrant genomes into inbred populations. Proc. R. Soc. Lond. Ser. B $269,1073-1078$

28 Paschke, M. et al. (2002) Effects of population size and pollen diversity on reproductive success and offspring size in the narrow endemic Cochlearia bavaria (Brassicaceae). Am. J. Bot. 89, 1250-1259

29 Beaumont, M.A. (2003) Conservation genetics. In Handbook of Statistical Genetics (Balding, D.J. et al., eds), pp. 751-792, John Wiley \& Sons

30 Ball, S.J. et al. (2000) The genetic contribution of single male immigrants to small, inbred populations: a laboratory study using Drosophila melanogaster. Heredity 84, 677-684

31 Charlesworth, D. (1985) Distribution of dioecy and self-incompatibility in angiosperms. In Evolution - Essays in Honor of John Maynard Smith (Greenwood, J.J. and Slatkin, M. eds), pp. 237-268, Harvard University Press

32 DeMauro, M.M. (1993) Relationship of breeding system to rarity in the Lakeside Daisy (Hymenoxys acaulis var. glabra). Conserv. Biol. 7, $542-550$

33 Reinartz, J.A. and Les, D.H. (1994) Bottleneck-induced dissolution of self-incompatibility and breeding system consequences in Aster furcatus (Asteraceae). Am. J. Bot. 81, 446-455

34 Ross, K.G. et al. (1993) Effect of a founder event on variation in the genetic sex-determining system of the fire ant Solenopsis invicta. Genetics 135, 843-854

35 Gemmell, N.J. et al. (2004) Mother's curse: the effect of mtDNA on individual fitness and population viability. Trends Ecol. Evol. 19, $238-244$

36 Gemmell, N.J. and Allendorf, F.W. (2001) Mitochondrial mutations may decrease population viability. Trends Ecol. Evol. 16, 115-117

37 Sakai, A.K. et al. (2001) The population biology of invasive species. Annu. Rev. Ecol. Syst. 32, 305-332

38 Ingvarsson, P.K. and Whitlock, M.C. (2000) Heterosis increases the effective migration rate. Proc. R. Soc. Lond. B. Biol. Sci. 267, 1321-1326

39 Whitlock, M.C. et al. (2000) Local drift load and the heterosis of interconnected populations. Heredity 84, 452-457
40 Laurance, W.F. and Cochrane, M.A. (2001) Special section: synergistic effects in fragmented landscapes. Conserv. Biol. 15, 1488-1489

41 Wade, M.J. and Goodnight, C.J. (1991) Wright's shifting balance theory: an experimental study. Science 253, 1015-1018

42 Boulding, E.G. and Hay, T. (2001) Genetic and demographic parameters determining population persistence after a discrete change in the environment. Heredity $86,313-324$

43 Edmands, S. and Timmerman, C.C. (2003) Modeling factors affecting the severity of outbreeding depression. Conserv. Biol. 17, 883-892

44 Burke, J.M. and Arnold, M.L. (2001) Genetics and the fitness of hybrids. Annu. Rev. Genet. 35, 31-52

45 Rieseberg, L.H. and Burke, J.M. (2001) The biological reality of species: gene flow, selection, and collective evolution. Taxon 50, 47-67

46 Grant, P.R. et al. (2003) Inbreeding and interbreeding in Darwin's finches. Evolution 57, 2911-2916

47 Ungerer, M.C. et al. (2003) Effects of genetic background on response to selection in experimental populations of Arabidopsis thaliana. Genetics 163, 277-286

48 Caswell, H. (2001) Matrix Population Models, Sinauer Associates

49 Wisdom, M.J. et al. (2000) Life-stage simulation analysis: estimating vital rate effects on population growth for conservation. Ecology 81, 628-641

50 Robert, A. et al. Releasing adults versus young in reintroductions: interactions between demography and genetics. Conserv. Biol. (in press)

51 Linklater, W.L. (2003) A novel application of the Trivers-Willard model to the problem of genetic rescue. Conserv. Biol. 17, 906-909

52 Mills, L.S. and Allendorf, F.W. (1996) The one-migrant-per-generation rule in conservation and management. Conserv. Biol. 10, 1509-1518

53 Wang, J. (2004) Application of the one-migrant-per-generation rule to conservation and management. Conserv. Biol. 18, 332-343

54 Roberts, S.C. and Gosling, L.M. (2003) Genetic similarity and quality interact in mate choice decisions by female mice. Nat. Genet. $35,103-106$

55 Swenson, J.B. et al. (1997) Infanticide caused by hunting of male bears. Nature 386, 450-451

56 Hogg, J.T. (2000) Mating systems and conservation at large spatial scales. In Vertebrate Mating Systems (Appolonio, M. et al., eds), pp. 214-252, World Scientific Press

57 Hess, G. (1996) Disease in metapopulation models: implications for conservation. Ecology 77, 1617-1632

$58 \mathrm{McCallum}, \mathrm{H}$. and Dobson, A. (2002) Disease, habitat fragmentation, and conservation. Proc. R. Soc. Lond. Ser. B 269, 2041-2049

59 Waples, R.S. and Drake, J. (2004) Risk/Benefit consideration for marine stock enhancement: a Pacific salmon perspective. In Stock Enhancement and Sea Ranching: Development, Pitfalls and Opportunities (Leber, K.M. et al., eds), pp. 260-306, Blackwell

60 Lynch, M. (1991) The genetic interpretation of inbreeding depression and outbreeding depression. Evolution 45, 622-629

61 Beaumont, M.A. and Rannala, B. (2004) The Bayesian revolution in genetics. Trends Genet. 5, 251-261

62 Fenster, C.B. and Galloway, L.F. (2000) Inbreeding and outbreeding depression in natural populations of Chamaecrista fasciculata (Fabaceae). Conserv. Biol. 14, 1406-1412

63 Fenster, C.B. and Galloway, L.F. (2000) Population differentiation in an annual legume: genetic architecture. Evolution 54, 1157-1172

64 Edmands, S. (1999) Heterosis and outbreeding depression in interpopulation crosses spanning a wide range of divergence. Evolution 53, $1757-1768$

65 Armbruster, P. et al. (1999) Evolutionary responses to environmental stress by the pitcher-plant mosquito, Wyeomyia smithii. Heredity 83 , $509-519$

66 Marr, A.B. et al. (2002) Heterosis and outbreeding depression in descendants of natural immigrants to an inbred population of song sparrows (Melospiza melodia). Evolution 56, 131-142

67 Marshall, T.C. and Spalton, J.A. (2000) Simultaneous inbreeding and outbreeding depression in reintroduced Arabian oryx. Anim. Conserv. $3,241-248$

68 Burton, R.S. (1990) Hybrid breakdown in developmental time in the copepod Tigriopus californicus. Evolution 44, 1806-1813

69 Burton, R.S. (1990) Hybrid breakdown in physiological response: a mechanistic approach. Evolution 44, 1814-1822 
70 Galloway, L.F. and Fenster, C.B. (2001) Nuclear and cytoplasmic contributions to intraspecific divergence in an annual legume. Evolution 55, 488-497

71 Edmands, S. and Burton, R.S. (1999) Cytochrome $c$ oxidase activity in interpopulation hybrids of a marine copepod: a test for nuclear-nuclear or nuclear-cytoplasmic coadaptation. Evolution 53, 1972-1978

72 Gharrett, A.J. et al. (1999) Outbreeding depression in hybrids between odd- and even-broodyear pink salmon. Aquaculture 173, 117-129

73 Darwin, C.E. (1883) The Variation of Animals and Plants Under Domestication, D. Appleton \& Co
74 Wright, S. (1931) Evolution in Mendelian populations. Genetics 16, 97-159

75 Wright, S. (1940) Breeding structure of populations in relation to speciation. Am. Nat. 74, 232-248

76 Hedrick, P. (1995) Gene flow and genetic restoration: the Florida panther as a case study. Conserv. Biol. 9, 996-1007

77 Hedrick, P. Neutral, detrimental, and adaptive genetic variation in conservation genetics. In Conservation Genetics in the Age of Genomics (Amato, G. et al., eds), Columbia University Press (in press)

78 Keller, L.F. et al. (2001) Immigration and the ephemerality of a natural population bottleneck: evidence from molecular markers. Proc. R. Soc. Lond. Ser. B 268, 1387-1394

\section{Important information for personal subscribers}

Do you hold a personal subscription to a Trends journal? As you know, your personal print subscription includes free online access, previously accessed via BioMedNet. From now on, access to the full-text of your journal will be powered by Science Direct and will provide you with unparalleled reliability and functionality. Access will continue to be free; the change will not in any way affect the overall cost of your subscription or your entitlements.

The new online access site offers the convenience and flexibility of managing your journal subscription directly from one place. You will be able to access full-text articles, search, browse, set up an alert or renew your subscription all from one page.

In order to protect your privacy, we will not be automating the transfer of your personal data to the new site. Instead, we will be asking you to visit the site and register directly to claim your online access. This is one-time only and will only take you a few minutes.

Your new free online access offers you:

- Quick search • Basic and advanced search form • Search within search results • Save search • Articles in press • Export citations - E-mail article to a friend • Flexible citation display • Multimedia components • Help files

- Issue alerts \& search alerts for your journal

http://www.trends.com/claim_online_access.htm 